\title{
2008/46
}

On the impact of labor market matching on regional disparities

Jo Tharakan and Jean-Philippe Tropeano 
CORE

Voie du Roman Pays 34

B-1348 Louvain-la-Neuve, Belgium.

Tel (32 10) 474304

Fax (32 10) 474301

E-mail: corestat-library@uclouvain.be http://www.uclouvain.be/en-44508.html 


\title{
CORE DISCUSSION PAPER \\ 2008/46
}

\section{On the impact of labor market matching on regional disparities}

\section{Joe THARAKAN ${ }^{1}$ and Jean-Philippe TROPEANO ${ }^{2}$}

\author{
August 2008
}

\begin{abstract}
We propose a model where imperfect matching between firms and workers on local labor markets leads to incentives for spatial agglomeration. We show that the occurrence of spatial agglomeration depends on initial size differences in terms of both number of workers and firms. Allowing for dynamics of workers' and firms' location choices, we show that the spatial outcome depends crucially on different dimensions of agents' mobility. The effect of a higher level of human capital on regional disparities depends on whether it makes workers more mobile or more specialized on the labor market.
\end{abstract}

Keywords: economic geography, local labor market, regional disparities, human capital.

JEL Classification: J61, J42, R12

\footnotetext{
${ }^{1}$ Department of Economics, Université de Liège; CORE, Université catholique de Louvain, Belgium and CEPR.E-mail: j.tharakan@ulg.ac.be

${ }^{2}$ INRA and Université de Grenoble 2, France. E-mail: tropeanoj@upmf-grenoble.fr
}

The authors thank K. Behrens, P. Monfort, J.P. Neary, J. Thisse and S. Weber for several useful comments and participants at the EEA congress in Lausanne, 2002 CEPR workshop in Vilars as well as participants at seminars at UCL, UCD and Liège. The first author is grateful to FNRS for financial support, whereas the second author acknowledges support from the Ministère de l'éducation, de la recherché et de la formation (Communauté française de Belgique), Convention 00/05-262.

This paper presents research results of the Belgian Program on Interuniversity Poles of Attraction initiated by the Belgian State, Prime Minister's Office, Science Policy Programming. The scientific responsibility is assumed by the authors. 



\section{INTRODUCTION}

Economic geography models which attempt to explain the spatial distribution of economic activity through the interaction of different economic agents are now part of our stock of knowledge. The explanations provided by these theoretical models include, among others, those which combine transport costs with economies of scale (see Fujita et al., 1999). However, empirical investigations such as those undertaken by Dumais et al. (1997) and Rosenthal and Strange (2004), show that labor pooling is one of the main reasons for agglomeration. These empirical findings furnish support for the following insightful observation related to human capital and spatial agglomeration made by Marshall (1920): "Employers are apt to resort to any place where they are likely to find a good choice of workers with the special skills they require; while men seeking employment naturally go to places where there are many employers who need such skills as theirs".

Certain authors have dealt with the question of human capital's importance in the spatial distribution of workers and firms (see below). But this important issue also has other facets which need to be explored further. An analysis of the impact of human capital on the spatial distribution of economic activity has to specifically take into account the role played by its main characteristics. Workers' skills can be general (determining the productivity for the task they perfectly match) and specific (determining the mobility between tasks). The specificity of human capital engenders imperfect matching between firms and workers. In addition, the interactions between firms and workers on labor markets are spatially localized. The combination of imperfect matching and geographically localized interactions confers oligopsonic power to firms. This has a significant impact on location decisions of economic agents through its effects on wages. A priori, a change in the level of human capital can lead either to a lower, or a higher mobility of workers between tasks. The former outcome would be the result if the change leads to an increase in the level of specific human capital. The latter effect would take place if the change leads to more general human capital.

There are a few papers closely related to the issue of human capital and location analyzed in our paper. They either assume a given spatial configuration (Hesley and Strange (1990) with symmetric cities; Abdel-Rahman and Wang (1995) with a single metropolis within a system of cities) or consider very particular degrees of human capital specificity (Matouschek and Robert- 
Nicoud (2004), where it is either general or completely firm specific) or else assume an exogenous local positive human capital externality (the "brain drain" literature, Miyagiwa, 1991; Reichlin and Rustichini 1998). Our paper contributes to this existing literature in three ways. We develop a theoretical model which demonstrates the link between the main characteristics of human capital and spatial location of both firms and workers. Moreover we characterize all possible spatial equilibria (agglomeration, dispersion as well as partial agglomeration) and by allowing for simple dynamics show the crucial importance of different dimensions of workers' and firms' spatial mobility on the spatial outcome. In this way we break new ground by endogenizing the spatial distribution of firms and workers and hence the local human capital externalities according to the degree of human capital specificity.

The aim of our paper is two-fold: First, we provide a simple setting in which both skill and spatial mismatch between firms and workers confer market power to employers. This market power explains spatial agglomeration of both workers and firms, even in the absence of strategic behavior by firms in the final goods markets. Second, we apply our framework of analysis to examine how certain public policies which modify the magnitude of both sources of mismatch influence the agents' location decisions and the resulting degree of regional disparity.

We start by identifying the forces of agglomeration and dispersion. Mobile workers have incentives to locate themselves close to a large number of firms in order to escape the market power of firms. But at the same time, in order to avoid urban costs, they prefer not to locate themselves in too densely populated areas. The locational incentives of firms are different. Since the regional profit of firms increases with the number of workers in that region, firms have an incentive to locate in densely populated areas. But at the same time, since profit decreases with competition, firms will want to locate in markets with few rivals.

We show that depending on the level of general human capital and urban costs, there exists at most two types of stable equilibria: a dispersed equilibrium where half of each type of agents locate in one region, and an agglomerated equilibrium where both types of agents are spatially agglomerated. Introducing simple dynamics for both workers' and firms' location choices, we identify the threshold in terms of region size difference above which regional disparities will emerge. We show that this critical threshold depends on firms' and workers' spatial mobility.

We then proceed to use our framework of analysis to examine the impact of human capital on regional disparity. Our key findings are as follows: if an increase in the level of human 
capital leads to greater mobility of workers between tasks, the economy is more likely to converge towards the dispersed equilibrium. Indeed, greater skill mobility reduces oligopsonic power and thereby decreases workers' incentives to migrate towards larger regions. These theoretical findings are empirically supported by Diamond and Simon (1990) who show that in more specialized cities, workers demand higher wages. Moreover, following Maurel and Sédillot (1999), our theoretical results are in accordance with the observation that industries such as book publishing or cutlery where a highly specialized work force is needed, are spatially concentrated.

Another result of our model is that there is a positive correlation between the size of the market and the degree of specialization. This prediction is confirmed empirically by Duranton and Jayet (2005) who show that very specialized occupations are over-represented in large French urban areas. While their main concern is the division of labor, our story is consistent with their empirical results. In a sense our model complements their theoretical model. Indeed, while they argue that specialized tasks are opened by firms in large markets only, we show that large markets are the result of highly specialized workers induced to agglomerate in the same area in order to avoid firms' oligopsonic power.

The remainder of the paper is organized as follows. Section 2 describes the model. In section 3 we analyze the equilibrium in the labor market and derive the regional wages and profits. In section 4, we analyze location decisions of agents separately and then examine how the interaction of these decisions leads to different spatial outcomes. Section 5 discusses how public policies can influence regional outcomes. Section 6 concludes.

\section{THE MODEL}

\section{Workers and Firms}

There are two regions, region $A$ and region $B$. In each region, there are both workers and firms. We assume that total population equals 1 and denote by $\alpha_{A}$ (respectively $\alpha_{B}=1-\alpha_{A}$ ) the share of the population of workers located in region $A$ (respectively in region $B$ ). Each region's population consists of mobile and immobile workers, both endowed with the same level of human capital $h$. This human capital determines a worker's productivity.

The total number of firms is exogenous and equal to $N$. We denote by $\beta_{A}$ the share of 
firms located in region $A$. We consider $N$ sufficiently high so as to be able to ignore the integer problem. Each firm incurs a fixed cost (which is not specified since we assume that the number of firms is exogenous) and produces a homogenous good with labor according to a non-increasing returns to scale technology given by $Y=h F(l)$ with $F^{\prime}>0$ and $F^{\prime \prime} \leq 0$ and where $l$ is the number of workers. Since our objective is to focus on the impact of matching in the labor market, we assume that all firms produce the same homogeneous good and are price takers on the goods market. Furthermore, assuming that trade between the two regional goods markets is costless, the price of the homogenous good is the same in both regions and can be normalized to one. With these assumptions, we rule out all interactions on the goods market and therefore, unlike in Krugman (1991a) and Ottaviano et al. (2002), they do not influence the location decisions of agents. ${ }^{1}$ In equilibrium, firms earn positive profits. We assume that all workers have an equal share of total profits.

Each region is a linear segment with a central business district (CBD) where firms are located and production takes place. ${ }^{2}$ Workers reside outside the city and commute to the CBD to work. Each worker consumes one unit of land and his commuting cost is linear in the distance travelled. We denote by $t(t>0)$ the unit commuting cost paid in the numéraire good. This parameter is identical in both regions. Urban costs incurred by the workers consist of land rent and commuting cost. We assume that the land rents collected are equally distributed among the workers. Under these assumptions, we show in the appendix that the urban cost of living in region $j$ incurred by a worker, $C\left(\alpha_{j}\right)$, is linear in the size of the population and given by $C\left(\alpha_{j}\right)=t \alpha_{j} / 4$. We should note that, unlike Brueckner et al. (2002), $C\left(\alpha_{j}\right)$, does not depend on worker income. This result arises from our assumption regarding commuting cost. Since we do not study the relationship between labor market and urban location (unlike Brueckner et al. (2002) which analyses interactions between local labor markets and intra-urban locations of workers but do not consider firms location choice), this assumption does not have major consequences for our analysis. The focus of our paper is the interaction between local labor markets and inter-regional (or inter-urban) locations of both firms and workers.

Both firms and mobile workers choose their spatial location. Firms choose their location in

\footnotetext{
${ }^{1}$ Another interpretation for this framework is that we are considering two regions in a small country for which product prices are given.

${ }^{2}$ See Fujita and Thisse (2002) for reasons why firms want to locate in the CBD.
} 
function of the profit they earn. The utility of workers is linear in income. We denote by $\alpha_{j}^{I}$ the proportion of immobile workers in each region $j$ with $\alpha_{j}^{I} \geq 0$. The presence of immobile workers captures the fact that some individuals have exogenous characteristics which causes them to have high mobility costs. These costs are so high that they do not move from one region to another despite possible wage differences between the two regions.

\section{The Labor Market}

Firms and workers are located in one region only and the labor market is local. Workers have heterogenous skills while firms are characterized by a particular technology. ${ }^{3}$ Since there is only a finite number of firms present in the labor market, there is a degree of mismatch between workers' skills and firms' skill requirements. Interaction on the labor market is modelled as in Hamilton et al. (2000). Skill space is represented by a circle of circumference one. Each firm and each worker has a specific position on the circle. For the worker, it represents the skills he possesses and for the firm it represents the skill requirement of its technology. Both firms and workers are assumed to be distributed uniformly over the circle. Only if his skills perfectly match the firm's technology can a worker produce output. If there is no perfect match between the two, then the worker has to undergo a training, the cost of which he bears. The training cost depends on the distance between the worker's skill and the firm's skill requirement. More specifically, if positions of worker and firm are given by $x$ and $x_{i}$, then the training cost function is given by $s(h)\left|x-x_{i}\right|$ where $s(h)$ is the unit training cost.

The main interpretation of parameter $h$ is the level of human capital. Following Becker (1964), we distinguish general human capital from specific human capital. An increase in the stock of specific human capital leads to an improvement of the worker productivity. Yet, this increase is biased toward the task for which the worker is trained. Thus in our framework, more specific human capital means an increase in $h$ combined with a rise of $s(h)$ which captures the increasing difficulty for a worker to move from one task to another. An improvement in the level of general human capital means that the worker increases his ability to perform different types of tasks. ${ }^{4}$ We capture such an improvement with a rise of $h$ and a simultaneous decrease

\footnotetext{
${ }^{3}$ As shown by Stevens (1994) firms have an incentive to differentiate their skill requirements in order to obtain market power in the labor market characterized by the heterogeneity of the workers' skills.

${ }^{4}$ While throughout the paper we talk about "training costs", it can represent any type of cost as, for instance, a loss of utility associated to the mismatch.
} 
in $s(h)$. The way we represent general human capital is close to Möbius and Schoenle (2006) since a skilled worker is characterized by his ability to move from one task to another. However unlike them, we do not consider multi-task firms.

We can also interpret $h$ as the aggregate productivity of the economy. In that case, an increase in $h$ is the result of technological change. Parameter $s(h)$ then captures the complementarity between the firm and the worker human capital. Thus, if the technological change is skill-biased, it disproportionately improves the efficiency of workers who fit best with the firm capital requirements. We follow here, among others, Marimon and Zilibotti (1999) or Krusell et al. (2000) who stress that this skill bias in technological change is mainly due to an increase in capital-skill complementarity. Therefore, such a biased technological change leads to an increase in $s(h)$. According to Marimon and Zilibotti (1999), such an increase in $h$ as well as in $s(h)$ characterized the technological shock experienced by OECD countries in the late 1990s. Hence, any comparative static on $h$ can be seen according to either the technological or the human capital view.

We assume that there is asymmetric information between workers and firms. Firms are not able to observe workers' positions on the circle. The only information they have is the distribution of workers in the skill space. Therefore firms set wages that do not depend on workers actual location on the circle/skill space. Similarly, workers do not observe the firms' positions before choosing the region where they will be working. Workers only know the number of firms in a particular region and form an expectation concerning the distance to the nearest firm.

Finally, the timing of the game is the following. In a first stage, mobile workers and firms simultaneously choose their region. In a second stage, firms compete on the local labor markets. In a third stage, workers locate within the region. Solving the game by backward induction, we first determine the location choice within the region and the land rent equilibrium. We show in the appendix that a worker located in region $j$ earning a wage $w_{j}$ net of training costs has a net utility equal to $w_{j}-C\left(\alpha_{j}\right)$. Second, we describe the wage setting process and then study the migration decisions and the spatial equilibria. 


\section{REGIONAL WAGES AND PROFITS}

Interactions on the labor market being local, regional wages and profits depend on each region's characteristics. These characteristics are population density and number of firms, determining jointly the region's size. Workers base their location decisions on the expected wage. This expected wage depends on gross wage and expected training cost. Firms infer the profit they will obtain in each region based on that region's population and number of firms. Consider a firm $i$ in region $j(j=A, B)$ located in the skill space at $x_{i}$. The labor supply to firm $i$ depends on its own wage $w_{i}$ as well as on wages $w_{i-1}$ and $w_{i+1}$ set by adjacent firms. Denote by $\widehat{x}$ (resp. $\widehat{y}$ ) the workers indifferent between working in firm $i$ or in firm $i-1$ (resp. in firm $i$ or in firm $i+1)$. This implies that the labor supply to firm $i$ is given by:

$$
l_{i}\left(w_{i}, w_{i-1}, w_{i+1}\right)=\alpha_{j}(\widehat{y}-\widehat{x})=\alpha_{j}\left(\frac{x_{i+1}-x_{i-1}}{2}+\frac{w_{i}}{s}-\frac{w_{i-1}+w_{i+1}}{2 s}\right)
$$

Hence profit is given by (for ease of notation we use $l_{i}$ for $l_{i}\left(w_{i}, w_{i-1}, w_{i+1}\right)$ )

$$
\pi_{i}=h F\left(l_{i}\right)-w_{i} l_{i}
$$

where firm $i$ maximizes its profit by choosing $w_{i}$. The $\mathrm{FOC}^{5}$ is (dropping the index $i$ for ease of notation)

$$
\frac{\partial l}{\partial w} h F^{\prime}(l)-l-w \frac{\partial l}{\partial w}=0 \text { with } \frac{\partial l}{\partial w}=\frac{\alpha_{j}}{s}
$$

This expression gives the effect of a change in the firm's own wage on its labor supply. The higher the population density, the smaller the wage increase needed to increase the labor supply to the firm. We focus here on the symmetric Nash equilibrium, that is an equilibrium where firms are equidistant ${ }^{6}$ and where $w_{i}=w$. Given symmetrically located firms on the circle, the number of workers per firm in region $j$ is given by $l_{j}=\alpha_{j} / \beta_{j} N$. We can derive the unique symmetric wage equilibrium:

$$
w_{A}\left(\alpha_{A}, \beta_{A}\right)=h F^{\prime}\left(\frac{\alpha_{A}}{\beta_{A} N}\right)-\frac{s}{\beta_{A} N}
$$

\footnotetext{
${ }^{5}$ It is easily established that the SOC is always verified.

${ }^{6}$ Following Economides (1989) and Kats (1995), the equidistant configuration of locations on the circle is likely to be an equilibrium outcome of a game in which firms choose their technologies prior to setting their wages. In our case, this has to be considered as an approximation. Allowing for asymmetric firm locations would only complicate computations without modifying the results.
} 
The equilibrium wage equals marginal productivity of labor (the wage that would prevail with perfect competition on the labor market) given by $h F^{\prime}\left(\alpha_{A} / \beta_{A} N\right)$ minus a term $s / \beta_{A} N$ which can be interpreted as the impact of imperfect competition on the labor market. In this model, imperfect competition results from imperfect matching between firms and workers. Firms benefit from such an imperfection: because workers cannot move to another firm at zero cost, firms can set wages lower than marginal productivity. Consequently, the higher the unit training cost $s$, the greater the oligopsonic power of the firm and the lower its wage. This oligopsonic power is however reduced by the number of firms in the region: an increase in the number of firms in a region reduces the cost for a worker to move to another firm. This intensifies competition between firms, and thus pushes the equilibrium wage up. The wage is also positively related to the number of firms through the impact of the number of firms on marginal productivity. Finally, expression (3) shows that an increase in the density of workers pushes wages down. As the density of workers increases, the number of workers a firm employs increases and the marginal productivity decreases because of diminishing returns. Consider a worker not yet located in a region. This worker only knows the number of firms located in that region but, beforehand, he does not know exactly the skill distance to the firm where he will be employed. If he expects firms to be symmetrically located on the circle, his net expected wage is the gross wage net of expected training cost $E(T C)$ :

$$
\begin{aligned}
\bar{w}_{A}\left(\alpha_{A}, \beta_{A}\right) & =w_{A}\left(\alpha_{A}, \beta_{A}\right)-E(T C) \\
& =w_{A}\left(\alpha_{A}, \beta_{A}\right)-s \int_{0}^{1 / 2 \beta_{A} N} u\left(2 \beta_{A} N\right) d u \\
& =h F^{\prime}\left(\frac{\alpha_{A}}{\beta_{A} N}\right)-\frac{5 s}{4 \beta_{A} N}
\end{aligned}
$$

Here again, the net expected wage increases as the number of firms within the region increases. However, here the effect of $\beta_{A}$ is stronger than it is for the worker who perfectly matches the skill needs of a firm since it also takes into account the effect on the training costs that the workers incur. Using equations (2) and (3), the equilibrium profit is given by

$$
\pi_{A}\left(\alpha_{A}, \beta_{A}\right)=h F\left(l_{A}\right)-h l_{A} F^{\prime}\left(l_{A}\right)+s \frac{l_{A}}{\beta_{A} N}
$$




\section{MIGRATION EQUILIBRIA AND SPATIAL DYNAM- ICS}

The previous section described wages and profits for given agents' locations. Since firms and mobile workers can move from one region to another, these locations are endogenous. We start by looking at location decisions for each agent separately and then analyze how the interaction of the migration behavior of the two types of agents yields the location equilibria.

\section{Migration Equilibria}

Firms. Firms' location choice is driven by the difference between profit earned in region $A$ and that earned in region $B$. This comparison is given by the following expression: ${ }^{7}$

$$
\begin{aligned}
\Delta \pi\left(\alpha_{A}, \beta_{A}\right) & =\pi_{A}\left(\alpha_{A}, \beta_{A}\right)-\pi_{B}\left(\alpha_{B}, \beta_{B}\right) \\
& =h\left[\left(F\left(l_{A}\right)-l_{A} F^{\prime}\left(l_{A}\right)\right)-\left(F\left(l_{B}\right)-l_{B} F^{\prime}\left(l_{B}\right)\right)\right]+\frac{s}{N}\left(\frac{l_{A}}{\beta_{A}}-\frac{l_{B}}{\beta_{B}}\right)
\end{aligned}
$$

Two forces influence firms' location choice, a "market size effect" and a "competition effect". In our setting, the relevant market size for a firm is the number of workers per firm denoted by $l_{i}$. Ceteris paribus, firms are induced to locate where the number of workers per firm is larger: we have $\partial \Delta \pi / \partial l_{A}>0$ and $\partial \Delta \pi / \partial l_{B}<0$. Hence, whenever $l_{A}>l_{B}$, that is whenever region $A$ is larger than region $B$ in terms of workers per firm, firms want to locate in region $A$. This force plays towards convergence of regions. Market power, on the contrary, leads firms to avoid locating in the region where the number of firms is larger. Ceteris paribus, whenever $\beta_{A}>\beta_{B}$, firms choose to locate in region $B$ (for given $l_{A}$ and $l_{B}, \partial \Delta \pi / \partial \beta_{A}<0$ and $\partial \Delta \pi / \partial \beta_{B}>0$ ): competition is a dispersion force.

Since $\partial \Delta \pi\left(\alpha_{A}, \beta_{A}\right) / \partial \beta_{A}$ is different from zero, there exists a well defined function $M\left(\alpha_{A}\right)$ that gives for any density of workers $\alpha_{A}$, the share of firms in region $A\left(\beta_{A}\right)$ such that profits in both regions are the same, i.e. $\Delta \pi\left(\alpha_{A}, \beta_{A}\right)=0$. Moreover, we have:

$$
M^{\prime}\left(\alpha_{A}\right)=-\frac{\partial \Delta \pi / \partial \alpha_{A}}{\partial \Delta \pi / \partial \beta_{A}}=-\frac{>0}{<0}>0
$$

The intuition behind this result is the following. Consider the following comparative static along curve $M$, starting from a point on this curve where region $A$ is the large region, i.e. $\alpha_{A}>1 / 2$. If the number of workers in region $A$ increases, because of the market size effect,

\footnotetext{
${ }^{7}$ Note that $\Delta \pi\left(\alpha_{A}, \beta_{A}\right)$ is a function of only $\alpha_{A}$ and $\beta_{A}$ since $\beta_{B}=1-\beta_{A}$ and $\alpha_{B}=1-\alpha_{A}$.
} 
region $B$ becomes less attractive for firms since $l_{A}$ increases while $l_{B}$ decreases. Thus, in order to maintain indifference between both regions, the number of firms located in region $B$ must be lower. In addition, the market size in region $B$ (the ratio $l_{B}$ ) must decrease. If ratios $l_{B}$ and $l_{A}$ would remain unchanged, region $B$ would be more attractive than region $A$ because of less competition and unchanged market size. Hence, for $\alpha_{A}>1 / 2$, an increase in the number of workers in region $A$ leads to a continuous decrease of $l_{B}\left(=\alpha_{B} / N \beta_{B}\right)$. Note moreover that whenever region $A$ is the larger region, the curve is located below the 45 degree line. Indeed, tougher competition $\left(\beta_{A}>\beta_{B}\right)$ must be offset by a larger market size $\left(l_{A}>l_{B}\right)$. This also implies that the firm size must be larger in the larger region.

Figure 1 represents function $M$ relating the labor force $\alpha_{A}$ of region $A$ (X-axis) with the share of firms in that region $\beta_{A}$ (Y-axis). The curve is symmetric with respect to point $(1 / 2,1 / 2)$. For $\alpha_{A}>1 / 2$, any increase in the ratio $s(h) / N$ magnifies the competition force relative to the market size effect and thus pushes the curve lower since firms' agglomeration increases.

Workers. Location decisions by mobile workers involve comparing net expected income in each region. The net expected income is given by net expected wage minus the region's urban cost. Indeed, since the share of profit a worker obtains is independent of his location, he bases his location decision on the expected wage difference. The reason for considering the expected wage is that before making his decision the worker only knows the number of firms in a particular region. He forms an expectation about his skill distance to the nearest firm. The difference between the net expected wage obtained in region $A$ and that in region $B$, in addition to the urban cost difference gives us:

$$
\begin{aligned}
\Delta w\left(\alpha_{A}, \beta_{A}\right) & =\bar{w}_{A}\left(\alpha_{A}, \beta_{A}\right)-\bar{w}_{B}\left(1-\alpha_{A}, 1-\beta_{A}\right)-\frac{t}{2}\left(\alpha_{A}-\frac{1}{2}\right) \\
& =h \underbrace{\left[F^{\prime}\left(l_{A}\right)-F^{\prime}\left(l_{B}\right)\right]}_{\text {Market size effect }}+\underbrace{\frac{5}{4} \frac{s}{N}\left(\frac{1}{\beta_{B}}-\frac{1}{\beta_{A}}\right)}_{\text {Competition force }}+\underbrace{\frac{t}{2}\left(\frac{1}{2}-\alpha_{A}\right)}_{\text {Congestion force }}
\end{aligned}
$$

Three different forces drive workers location choice: a "competition force" (agglomeration force) as well as a "market size effect" and a "congestion force" (dispersion forces). Consider each of these forces in turn. Because of non-increasing returns, ceteris-paribus, workers are induced to locate where the number of workers relative to the number of firms is smaller. As in the case of 
firms, this force encourages convergence of regions in terms of $l_{i}$. Congestion costs lead workers to locate in the smaller region in terms of workers and thus constitute a dispersion force. As firms agglomerate in region $A$, the wage difference increases; tough competition on the labor market is an agglomeration force for workers. Stated differently, imperfect matching on the labor market confers market power to firms and leads workers to move to the region where a larger number of firms are located. Since $\partial \Delta w\left(\alpha_{A}, \beta_{A}\right) / \partial \beta_{A}$ is different from zero, there exists a function $G\left(\alpha_{A}\right)$ that gives for any density of workers $\alpha_{A}$, the share of firms in region $A$ $\left(\beta_{A}\right)$ such that net expected wages in both regions are the same, i.e. $\Delta w\left(\alpha_{A}, \beta_{A}\right)=0$. Thus we have:

$$
G^{\prime}\left(\alpha_{A}\right)=-\frac{\partial \Delta w / \partial \alpha_{A}}{\partial \Delta w / \partial \beta_{A}}=-\frac{<0}{>0}>0
$$

Indeed, if the number of workers becomes larger in region $A$, because of both the market size effect and the congestion force, workers prefer locating in region $B$. So as to restore the indifference, the number of firms in $B$ must be lower. However, because of the congestion force, there is no reason for the ratio $l_{B}$ to fall. Thus, a priori, curve $G$ could be either concave or convex. Graphically, this gives us the curve $G$ represented on Figure $1 .{ }^{8}$

\footnotetext{
${ }^{8} \mathrm{G}$ does not reach point $(1,1)$. Indeed, as the number of firms goes to zero in one region, oligopsonic power becomes infinite. Thus workers never locate in a region if the number of firms tends to zero.
} 


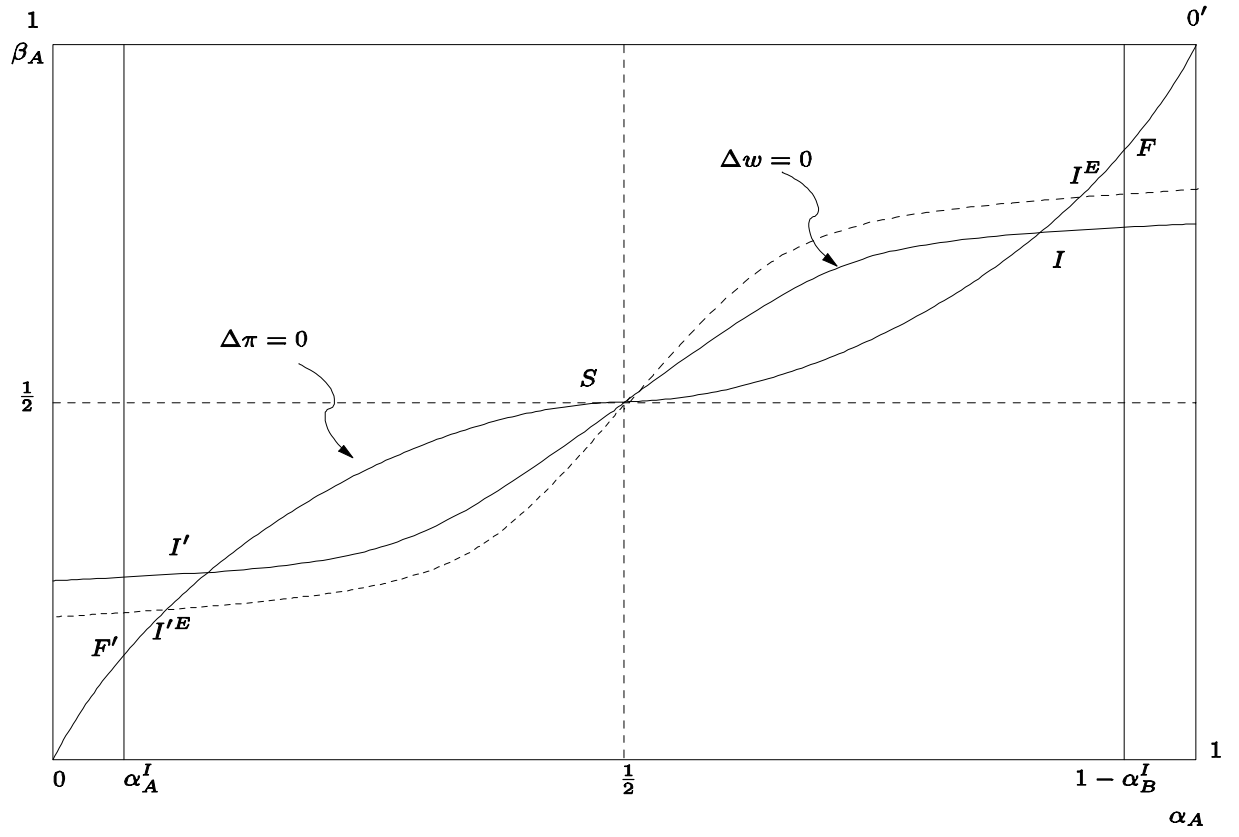

Figure 1

For $\alpha_{A}>1 / 2$, any increase in $t$ increases the congestion force relative to the market size force and pushes the curve up while any increase in the ratio $s(h) / N$ magnifies the competition force relative to the market size force and pushes the curve down.

Spatial Equilibria. In order to get the spatial distribution of economic activity, we must deal with the location decisions of both types of agents. An (interior) equilibrium is characterized by:

$$
\Delta w\left(\alpha_{A}, \beta_{A}\right)=0 \text { and } \Delta \pi\left(\alpha_{A}, \beta_{A}\right)=0
$$

There always exists a "symmetric equilibrium" where $\alpha_{A}=\alpha_{B}=1 / 2$ and $\beta_{A}=\beta_{B}=$ $1 / 2$. Moreover, the preceding section showed that the position of both curves depends on the ratio $s(h) / N$ whereas the position of the curve of workers depends also on $t$. Hence, if commuting cost $t$ is low (more precisely if $t<\underline{t}(h, s(h), N)),{ }^{9}$ then, in addition to the symmetric

\footnotetext{
${ }^{9} \underline{t}$ as well as $\overline{\mathrm{t}}$ are defined in the appendix.
} 
equilibrium, the "agglomeration" outcomes are also equilibria. In Figure 1, this configuration corresponds to point $\mathrm{F}\left(\mathrm{F}^{\prime}\right)$ when some workers are immobile and $0\left(0^{\prime}\right)$ when all workers are mobile. In this case the equilibria are characterised by $\Delta \pi\left(\alpha_{A}, \beta_{A}\right)=0$ and $\Delta w\left(\alpha_{A}, \beta_{A}\right)>$ $(<) 0$. The reason is that both firms and workers find it better to locate where other agents are located: firms accept to locate close to other firms and face stronger competition provided that the market is sufficiently large. This is guaranteed by the fact that workers, in order to obtain higher wages and because of low urban costs, want to locate where most firms are. If, on the contrary, commuting cost $t$ is extremely high $(t>\bar{t}(h, s(h), N))$, then the symmetrical outcome is the only equilibrium (In Figure 1, this would be a curve $G$ above curve $M$ for any $\alpha_{A}>1 / 2$ ). In this case, both agents want to avoid locating in a large region: workers want to avoid high urban costs and firms want to avoid competition since this is not compensated by a larger market. For intermediate values of $t$, i.e. $\underline{t}(h, s(h), N)<t<\bar{t}(h, s(h), N)$, there are three types of equilibria: the "full" agglomeration equilibria, the symmetrical outcome and the intermediate agglomeration (the configuration represented in Figure 1). This last type of equilibrium is an "asymmetric-interior" distribution of both firms and workers at points $I$ and $I^{\prime}$. Firms and workers are agglomerated within one region but, this agglomeration is not complete: some mobile workers and firms remain located in the other region. At points $I$ and $I^{\prime}$, given $t$, the asymmetric distribution of mobile workers between the two regions guarantees that the two net expected incomes are identical in both regions. In the larger region, a higher net expected wage due to stronger competition between firms is compensated by larger urban costs. We should note here that the uniqueness of points $I$ and $I^{\prime}$ is guaranteed if curve $G$ is concave and $M$ is convex.

\section{Spatial Dynamics}

Since we have multiple equilibria, the equilibrium that will be selected depends both on initial conditions as well as adjustment speeds of both types of agents. For simplicity, we focus in this section on the case where point $I$ is unique. However, similar spatial dynamics can be established in the more general case. To start with, let us assume that both agents will move to the region with the highest current payoff. Initial distributions of workers and firms that, independently of adjustment speeds, always lead the economy to the symmetrical outcome $S$, are contained in the rectangle whose corners are given by intermediate agglomeration points $I$ and $I^{\prime}$ (Figure 2). The size of this rectangle depends on the parameters of the model. Any policy 
that increases the size of this rectangle increases the probability that regions converge. However, the points within this "S-box" are not the only initial conditions that lead the economy to the $S$ outcome. In order to identify all the initial conditions that will lead to $S$ we need to make assumptions on the migrating behavior and adjustment speeds of the two types of agents. We assume the following functional forms for the migration functions:

$\dot{\alpha}_{A}=\left\{\begin{array}{c}\mu\left(\Delta w\left(\alpha_{A}, \beta_{A}\right)\right)>0 \text { if } \Delta w\left(\alpha_{A}, \beta_{A}\right)>0 \text { and } \alpha_{A}<1-\alpha_{B}^{I} \\ 0 \text { if either } \Delta w\left(\alpha_{A}, \beta_{A}\right)=0 \text { or if } \Delta w\left(\alpha_{A}, \beta_{A}\right) \neq 0 \text { and } \alpha_{A}<\alpha_{A}^{I} \text { or } 1-\alpha_{B}^{I}<\alpha_{A} \\ \mu\left(\Delta w\left(\alpha_{A}, \beta_{A}\right)\right)<0 \text { if } \Delta w\left(\alpha_{A}, \beta_{A}\right)<0 \text { and } \alpha_{A}^{I}<\alpha_{A}\end{array}\right.$

$\dot{\beta}_{A}=\left\{\begin{array}{c}v\left(\Delta \pi\left(\alpha_{A}, \beta_{A}\right)\right)>0 \text { if } \Delta \pi\left(\alpha_{A}, \beta_{A}\right)>0 \text { and } \beta_{A}<1 \\ 0 \text { if } \Delta \pi\left(\alpha_{A}, \beta_{A}\right)>0 \text { and } \beta_{A}=1 \text { or } \Delta \pi\left(\alpha_{A}, \beta_{A}\right)<0 \text { and } \beta_{A}=0 \text { or } \Delta \pi\left(\alpha_{A}, \beta_{A}\right)=0 \\ v\left(\Delta \pi\left(\alpha_{A}, \beta_{A}\right)\right)<0 \text { if } \Delta \pi\left(\alpha_{A}, \beta_{A}\right)<0 \text { and } 0<\beta_{A}\end{array}\right.$

where functions $\mu$ and $v$ are assumed non-decreasing and continuous.

Note that here we are assuming that agents have myopic expectations and take decisions in function of current values only. This means that only history matters. It is a common assumption in this type of models. Another possibility would be to assume that agents have forward-looking expectations. ${ }^{10}$ At the end of this section, we discuss what the implications could be if workers were to have forward-looking expectations.

For our analysis we focus on the case where there are five different spatial equilibria which corresponds to the situation where $t$ has an intermediate value, $G$ is concave and $M$ is convex. In the appendix, we show, that equilibria $F$ and $F^{\prime}$ as well as equilibrium $S$ are stable. Points $I$ and $I^{\prime}$, on the contrary, are saddlepoints. The two stable paths associated with the saddlepoints divide the complete space of initial conditions into three basins of attraction, one for each stable equilibrium. Besides the elements that determine the size of the "S-box", the size of each basin of attraction also depends on the relative adjustment speeds of the agents. This can be explained as follows. The critical size threshold above which a region converges to

\footnotetext{
${ }^{10}$ For a summary of this issue, see Krugman (1991b), Fukao and Benabou (1993) and Baldwin (2001).
} 
full agglomeration depends on the population and the number of firms. However, the relative importance of these two elements in determining the threshold is a function of the speeds of adjustment: at given adjustment speed of workers, the greater the speed of adjustment of firms, the less important is the number of firms. Consider point $J$ in Figure 2. Since this point is at the right of $\bar{\alpha}$, the economy would be completely agglomerated if firms' adjustment speeds were infinite. But, whenever there is some inertia in their location decisions, the combined dynamics lead the economy to a completely different outcome, namely the symmetrical equilibrium. The explanation is the following. At point $J$, workers of region $A$ have an incentive to move to region $B$ because the number of firms is not sufficiently large. At the same time, there is an entry of firms in region $A$ because the number of workers there is large. If firms' adjustment speed is sufficiently important, a threshold will be reached where the mass of firms in region $A$ is important enough to attract workers to region $A$ again. If not, then on the contrary, another threshold will be reached in terms of population size such that firms no longer want to move into region $A$. The impact of different adjustment speeds of agents on the selection of the spatial equilibrium suggests that countries which have initially similar regional asymmetries could experience very different outcomes. Starting from $J$, a country like the US might end up in point $S$ while the EU might reach point $F$. Point $J$ for a country like the US, where workers' mobility is high, might not be in the basin of attraction of point $F$, thus ending up at point $S$ while for the EU, where typically workers are less mobile (Bentivogli and Pagano, 1999), it might, on the contrary, be in the basin of attraction of point $F$. 


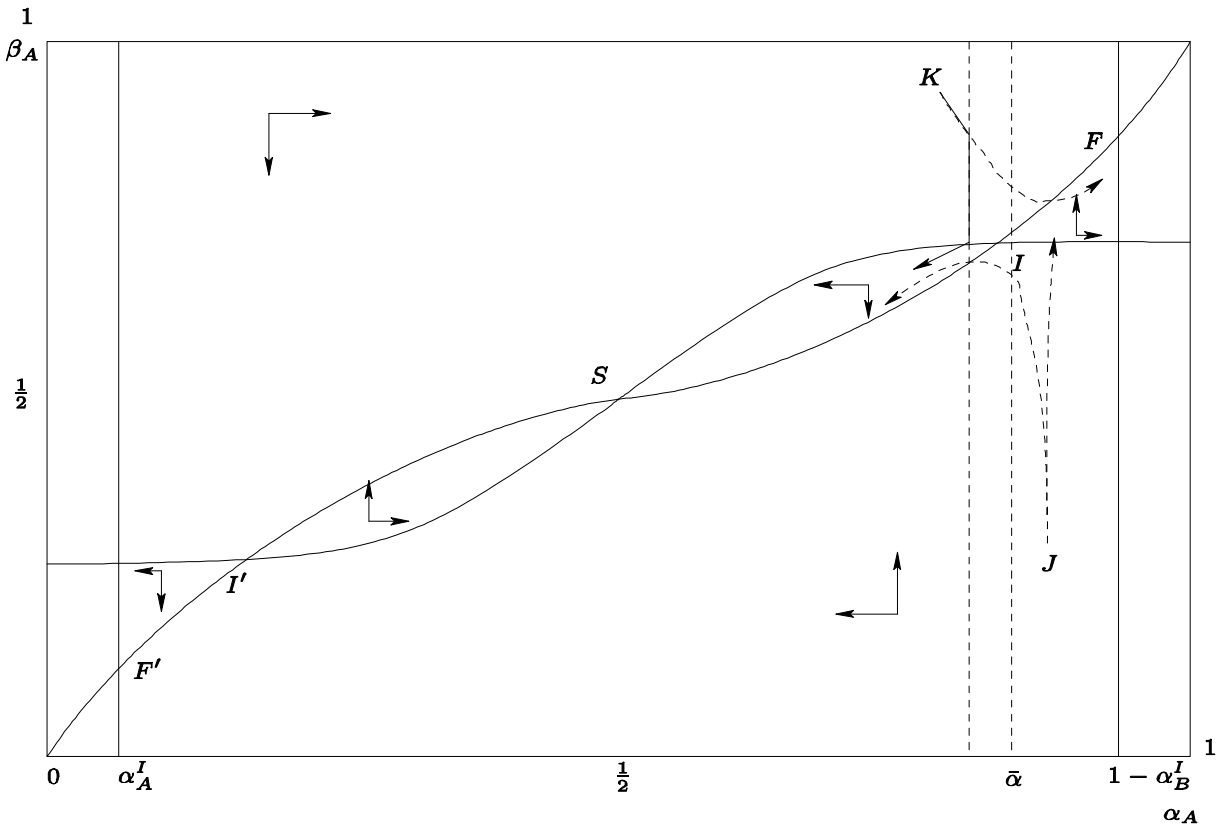

Figure 2

Our model's main result is the existence of a size difference threshold: initial regional size asymmetries greater than this threshold ( $\bar{\alpha}$ or $\bar{\beta}$ for extreme adjustment speeds) result in agglomeration of agents in one region through a self-reinforcing process. Public policy changes regional outcomes by modifying this threshold's level: the higher it is, the less likely the economy converges towards full agglomeration. It also shows why with strong differences in adjustment speeds of different agents, the same public policy has in some cases a limited impact while in other cases the effect will be dramatic.

Until now we assumed that agents moved in function of current wage differences. Myopic dynamics give only a partial picture of what dynamics could be. How would our results change if agents adopt a forward-looking behavior and made their decisions in function of future values? For simplicity, let us assume that the production function is linear and that firms adjust themselves instantaneously. As before, if $t<\underline{t}(h, s(h), N)$, then only the symmetrical and two agglomeration points are equilibria. If $t$ is very low, rendering the large region more attractive, then expectations can play if regions are initially not too different in size. For 
instance, a trajectory where the initial larger region becomes the smaller is consistent with rational expectations. If $t$ is higher, then expectations do not play any role and the initially larger region eventually attracts all activity whereas whenever regions are quite similar the economy converges toward the symmetric equilibrium. Indeed, it would be too costly for workers to move toward one region even if they all expect that region to become larger in the future. If $t>\bar{t}(h, s(h), N))$, then there are five equilibria possible. Here again, if $t$ is not too high, adjustment costs and discount factor are low, expectations can play a role if the regions are neither too different nor too similar in size.

\section{PUBLIC POLICIES AND REGIONAL OUTCOME}

The previous section showed that agents' location decisions depend on three parameters: level of urban cost, share of immobile workers and level of human capital. In this section, we show how changes in these parameters influence the stability and the existence of different spatial equilibria. In doing so, we are able to examine the impact of different types of mobility, mobility within regions, mobility between regions and mobility on the labor market, on regional disparities as well as on social welfare. Hence our main question: For each type of mobility, will its improvement increase or decrease the likelihood of agglomeration?

We show that any improvement of spatial mobility is likely to increase regional disparities whereas improving mobility on the labor market is likely to reduce such disparities.

\section{Workers' Spatial Mobility}

Spatial mobility has two dimensions: mobility between and within regions. Increasing mobility within regions unambiguously magnifies the agglomeration process. A fall in commuting cost $t$ decreases the magnitude of the congestion force. Thus, for any $t<\bar{t}$, the agglomerated equilibrium always exists. For values below $\underline{t}$, the economy is likely to fully agglomerate.

Similarly if more workers are mobile between regions, agglomeration becomes more likely. Consider point $\mathrm{K}$ in figure 2. Two cases are illustrated. If the number of immobile workers in region $B$ is large (upper boundary left of $\bar{\alpha}$ ), then the economy always converges toward the symmetrical equilibrium. The reason is that given the large number of immobile workers in $B$, region $A$, initially larger and with higher wages, will lose firms since it will never be able to reach a sufficiently important market size to compensate firms for a higher degree of 
competition. If the number of immobile workers in region $B$ is small (upper boundary right of $\bar{\alpha}$ ), the economy is likely to converge toward agglomeration if the initial size of region $A$ is sufficiently large. As in other models, high interregional mobility allows one region to attract a sufficient number of workers to sustain agglomeration.

\section{Education and Spatial Equilibria}

In our model, an improvement in the education of workers takes the form of an increase in the level of human capital $h$. Such a policy has a direct positive impact on the productivity of workers as well as an indirect impact on the degree of specialization of workers, which is measured by the term $s(h)$. There are two possibilities: an increase in the level of human capital can make workers either less $\left(s^{\prime}(h)<0\right)$ or more $\left(s^{\prime}(h)>0\right)$ specialized. We show that the impact of education on regional disparities depends crucially on its effect on specialization: increasing the level of human capital increases the incentives for workers to agglomerate and increases the size of the basin of attraction of agglomeration equilibria only if it leads to more specialization.

Consider the case with immobile workers in region $B$ and agglomeration in region $A$ (point $F$ in Figure 1). A change in the level of human capital modifies the relative importance of forces (competition, congestion and market size force) working in different directions. Assume to start with that $h$ has no influence on $s(h)$. Then, an increase in $h$ increases, relative to both competition and congestion forces, the importance of the market size force, which, because of the productivity difference tends to lead to a convergence of the firms per worker ratio $\left(\partial \Delta \pi / \partial h_{\mid \Delta \pi=0}<0\right)$. In the same way, incentives for workers to agglomerate are reduced $\left(\partial \Delta w / \partial h_{\mid \Delta w=0}<0\right)$. If $h$ has a negative impact on $s(h)$, the same remains true and the dispersion effect is even reinforced since the competition force plays a smaller role. Consequently, if the increase in $h$ is sufficiently large, ceteris paribus, the agglomerated equilibrium no longer exists. ${ }^{11}$ In that case, the threshold $\bar{\alpha}$ increases so that the basin of attraction of the agglomerated equilibrium becomes smaller, thereby decreasing the likelihood of the economy converging to this equilibrium. ${ }^{12}$ We should note here that the negative impact of $h$ on $s(h)$ increases competition and thus reduces the wage mark-up.

\footnotetext{
${ }^{11}$ Indeed, according to equation (6) a decrease in $s$ has a similar impact as an increase in $t$.

${ }^{12}$ When the agglomeration force decreases, curve $G$ rotates counter-clockwise. There exists an $s$ such that $G$ is fully above the 45 degree line and point $I$ no longer exists. Thus by continuity, $\bar{\alpha}$ increases.
} 
On the other hand, if specialization increases following an increase of $h\left(s^{\prime}(h)>0\right)$, the magnitude of the competition force increases: firms are more sensitive to competition and thus are induced to locate where the number of firms is lower, whereas as competition on the labor market weakens, workers' incentives to agglomerate within the larger region increase. Hence, if $s^{\prime}(h)>0$, an increase in $h$ generates two opposing forces: one based on productivity differences encouraging dispersion and another one based on labor market competition encouraging agglomeration of workers. In that case, education policy reduces competition on the labor market and thus increases the wage mark-up.

Therefore, the impact of an increase in human capital depends crucially on its effect on specialization. A decrease in specialization unambiguously fosters dispersion while a specialization increase is likely to lead to more agglomeration.

An education policy will be able to reduce regional disparities if it reduces workers' specialization. In other words, to reduce regional disparities, general training, which makes workers more mobile between tasks, is to be preferred to specific training. This point can be illustrated with experiences of countries like the Czech Republic and Poland. The existence of education structures leading to a workforce which was too specialized was seen as a major barrier to their development. Recently, these countries have tried to make vocational programs more general (Gill et al., 2000). Moreover, a recent study on French micro data (Drapier and Jayet, 2003) on spatial mobility of young workers supports our results. Indeed, the authors show that young low-skill and very specialized workers move much more than high-skill and less specialized workers. The authors explain this observation by the fact that skill mismatch is much more common among low-skill than among the high-skill workers. Going back to Figure 2 , this might be another reason why a country like the US is more likely to end up at point $\mathrm{S}$ than the EU: in the US the focus is more on general education while in the EU the focus is more on vocational education (specific human capital) (Krueger and Kumar 2004; Wasmer 2006).

If we follow our technological interpretation of parameter $h$, an increase in $h$ is seen as technological progress. In that case, according to our previous discussion, we show that a biased technological progress that reinforces complementarity between skilled workers and firms is likely to lead to spatial agglomeration.

Martin (1999) and Matouschek and Robert-Nicoud (2005) are examples of a few existing 
economic geography models which introduce human capital. Although we are using a different approach, our main conclusion on the impact of education improvement on regional disparities is in line with Martin (1999). He shows that an increase in the researchers' productivity reduces regional inequality by inducing more entry on the goods market. Our results are somewhat different than those of Matouschek and Robert-Nicoud (2004). In a model with endogenous investment in human capital, they show that if workers have the possibility to invest only in industry-specific human capital, they are likely to agglomerate while if the only possibility is firm-specific human capital, dispersion is more likely. With pure industry-specific human capital, their results depend on the assumption that there are only two firms. If human capital is industry-specific, both firms no longer have market power if they both locate in the same region whereas spatial dispersion confers monopoly power to each firm. In our model, the magnitude of oligopsonic power depends on both the specificity of human capital as well as on the number of firms. And in our case, we show that the less industry-specific (the more firm-specific) the human capital, the more likely is the agglomerated equilibrium.

Finally, what can be said regarding the welfare impact of an education policy? To analyze this, we use a simple measure of total welfare. In this economy with only one final good, a natural measure of welfare is given by total production minus total training cost and the urban cost. ${ }^{13}$ Total welfare of both regions is given by:

$$
\begin{aligned}
& W\left(\alpha_{A}, \beta_{A}\right)=\underbrace{N \beta_{A} h F\left(\frac{\alpha_{A}}{N \beta_{A}}\right)+\left(N-N \beta \alpha_{A}\right) h F\left(\frac{1-\alpha_{A}}{N-N \beta_{A}}\right)}_{\text {Total production }} \\
& -\underbrace{2 N \beta \int_{0}^{1 / 2 N \beta_{A}} s u \alpha_{A} d u-2\left(N-N \beta_{A}\right) \int_{0}^{1 / 2\left(N-N \beta_{A}\right)} s u\left(1-\alpha_{A}\right)}_{\text {Total training cost }} d u \\
& -\underbrace{\frac{t}{4}\left(\alpha_{A}^{2}+\left(1-\alpha_{A}\right)^{2}\right)}_{\text {Total urban cost }}
\end{aligned}
$$

Education improvement has two distinct effects on aggregate welfare. For unchanged agents location, a decrease in $s$ or an increase in $h$ has a positive impact on welfare. However, as

\footnotetext{
${ }^{13}$ Indeed, because of inelastic labor supply and housing demand, and the existence of only one consumption good, utility increases with output. As a result, total production is an utilitarian measure of welfare: if total production increases, there are individual transfers that ensure that all profits and all individual utilities increase.
} 
explained above, an education policy is also likely to modify the spatial equilibrium of the economy.

It is impossible to give general conclusions regarding which spatial equilibrium, $S$ or $F$, dominates in terms of welfare. The welfare ranking of these two points depends on the specific parameter values. Point $S$ dominates point $F$ in terms of total production because of nonincreasing returns and in terms of large urban costs while point $F$ leads to lower total training costs even though immobile workers remaining in the small region face higher training costs. A higher $h$, a lower $s$, and a higher $t$ make it more likely that point $S$ dominates point $F$ in terms of welfare and vice versa.

From our previous discussion of the effect of an increase in $h$ on spatial equilibrium, we know that the nature of the education policy is of crucial importance for the spatial outcome. If the objective is to avoid strong regional inequalities where most economic activity is located in one region, an education policy which increases not only worker productivity but also renders workers more mobile between tasks should be favored. This reduces incentives for workers to agglomerate in the large region to avoid firms' market power and hence reduces the likelihood of an agglomerated outcome. An education policy rendering workers less mobile between tasks would have the opposite effect. If we analyze the two types of education policies in terms of their welfare impact, results are less clear-cut. An education policy rendering workers more mobile between tasks, makes the symmetrical outcome more likely and also increases the likelihood of $S$ being better in terms of welfare. The second type of education policy makes the agglomerated outcome $F$ more likely, but it also reduces the likelihood that $S$ dominates in terms of welfare. The explanation for this result is that agents partly internalize the impact of a change in $h$ or $s$ in their location decisions. However, we cannot exclude the fact that the spatial outcome is the dominated spatial equilibrium. For workers, the private benefit of agglomeration is higher than the social benefit since they are induced to escape from market power whereas for firms, for the same reason, the private benefit of dispersion is higher than the social benefit (at point $F$, we have that $\left.\partial W / \partial \beta_{A}>0\right)$.

Finally, although we modelled a public education policy simply as an exogenous increase in parameter $h$, this can be modelled explicitly. One possible approach is to adopt the framework proposed in De la croix and Michel (2005). Individuals have the choice to spend their wages either on consumption or on education. By taxing wages and spending tax revenue on edu- 
cation, prices are distorted in such a way that individuals are incited to spend more on their education and hence accumulate more human capital.

\section{Human Capital and Spatial Mobility}

Until now we assumed exogenously that some workers were mobile while others were not. Similar results are obtained if all individuals are geographically mobile, i.e. $\alpha_{A}^{I}=\alpha_{B}^{I}=0$, but their incentives to relocate vary with their level of human capital. Assume two types of workers: $\alpha^{E}$ educated workers of type E with human capital $h^{E}$ and $\alpha^{U}$ unskilled workers of type U with human capital $h^{U}$, with $h^{E}>h^{U}$ and $\alpha^{E}+\alpha^{U}=1$. For simplicity, assume that the production function is separable in worker type, that there are constant marginal productivities and we focus here on the case where $s(h)$ increases with $h$. In that case, curve I'SI $\left(I^{E} S I^{\prime E}\right)$ gives the distribution of workers and firms between the two regions such that U-type (E-type) workers are indifferent between the two locations. With this production function specification, the regional wage depends only on the number of workers located in the region and not on the distribution of different types of workers. This means that as discussed in section 5.2, the exact position of each curve depends on the level of $h$. In addition to points 0 , S, and 0 ', the existence of other equilibria depends on the number of each worker type. With a small number of U-type workers (and hence a large number of E-type workers), point $I^{E}\left(I^{\prime E}\right)$ is an equilibrium in which all U-type workers agglomerate in the large region; If this number is large, point I (I') is an equilibrium in which not all but most U-types agglomerate in the large region; If the shares of both types of workers are not too different, both $I^{E}\left(I^{\prime E}\right)$ and I (I') are equilibria.

This brief consideration of two worker types with different levels of human capital improves our understanding of the interaction between level of human capital and location decisions. We show that the unskilled workers are those who are the most induced to agglomerate to avoid market power from firms since any kind of agglomerated equilibrium consists of the agglomeration of the unskilled. In that sense the unskilled workers are "more mobile". An increase in the urban cost leads to a counter-clockwise rotation around point $\mathrm{S}$ of the two $\mathrm{G}$ curves. The intuition for this is that for $\alpha_{A}>1 / 2$, if urban costs are higher, at a given distribution of total population between the two regions, both types of workers would only be willing to stay in the large region if there are higher wages. This means that both points $I$ and $I^{E}$ move towards 0 '. The result is that for a given total number of U-type workers, the 
complete agglomeration of all U-type workers in the large region is more likely. Higher urban costs require attracting more firms, which itself is only possible if the large region is bigger in terms of population. The increase in size of the larger region allows a bigger share of U-type workers, who have the most incentives to locate in the large region, to agglomerate.

\section{CONCLUSION}

We show in this paper how labor market imperfection due to human capital specificity can give rise to regional disparities. The specificity of human capital gives oligopsony power to firms. Workers thus have incentives to move to regions where a large number of firms are located while firms benefit from large labor markets. We identify a regional size difference threshold above which regional disparities will emerge.

In this framework, we show that a policy which increases workers' mobility between jobs or tasks, increases competition on the labor market and thus makes workers less likely to move from the less to the most populated region. This suggests that if regional equality is the objective, not all types of education policies are suited: only those policies which increase workers' labor market mobility decrease the probability of regional disparity.

\section{APPENDIX}

\section{Urban Cost}

As in Brueckner at al. (2002) or Fujita and Thisse (2002), the utility of a worker within a region $j$ with a mass of $\alpha_{j}$ workers is determined as follows. We define $z$ as the numéraire good consumed by workers. Denoting by $R(x)$ the rent per unit of land located at a distance $x$ from the $\mathrm{CBD}$ and considering a worker that has a wage (net of training costs) equal to $w$ located at a distance $x$ from the $\mathrm{CBD}$, the budget constraint is: $R(x)+t x+z=w$. Thus the bid-rent is given by $R(x)=w-z-t x$. Considering without loss of generality that the opportunity cost of land is zero, the rent at the fringe of the city $\left(x=\alpha_{j} / 2\right)$ is zero: $R\left(\alpha_{j} / 2\right)=0$. Hence $z=w-t\left(\alpha_{j} / 2\right)$. We assume that all the land rents are collected and equally redistributed among the workers of the region. Consequently, individual urban costs after redistribution of land rents are equal to $t \alpha_{j} / 4$. 
Functions $M\left(\alpha_{A}\right)$ and $G\left(\alpha_{A}\right)$

We start by showing that both functions are increasing and then show the convexity of $M\left(\alpha_{A}\right)$ in general and the concavity of $G\left(\alpha_{A}\right)$ in special cases. We set $F_{j}^{\prime \prime} \equiv F^{\prime \prime}\left(\alpha_{j} / N \beta_{j}\right)$.

Monotonicity of $M\left(\alpha_{A}\right)$ and $G\left(\alpha_{A}\right)$

$$
\begin{aligned}
& \frac{\partial \Delta \pi}{\partial \alpha_{A}}=-\frac{h}{N} \frac{l_{A}}{\beta_{A}} F_{A}^{\prime \prime}+\frac{s}{\beta_{A}^{2} N^{2}}-\frac{h}{N} \frac{l_{B}}{\left(1-\beta_{A}\right)} F_{B}^{\prime \prime}+\frac{s}{\left(1-\beta_{A}\right)^{2} N^{2}}>0 \\
& \frac{\partial \Delta \pi}{\partial \beta_{A}}=h \frac{l_{A}^{2}}{\beta_{A}} F_{A}^{\prime \prime}-\frac{2 s l_{A}}{\beta_{A}^{2} N}+h \frac{l_{B}^{2}}{\left(1-\beta_{A}\right)} F_{B}^{\prime \prime}-\frac{2 s l_{B}}{\left(1-\beta_{A}\right)^{2} N}<0
\end{aligned}
$$

Similarly,

$$
\begin{aligned}
& \frac{\partial \Delta w}{\partial \alpha_{A}}=\frac{h}{N} \frac{F_{A}^{\prime \prime}}{\beta_{A}}+\frac{h}{N} \frac{F_{B}^{\prime \prime}}{1-\beta_{A}}-\frac{t}{2}<0 \\
& \frac{\partial \Delta w}{\partial \beta_{A}}=-\frac{h}{N} \frac{F_{A}^{\prime \prime} \alpha_{A}}{\beta_{A}^{2}}-\frac{h}{N} \frac{F_{B}^{\prime \prime}\left(1-\alpha_{A}\right)}{\left(1-\beta_{A}\right)^{2}}+\frac{5 s}{4 N\left(1-\beta_{A}\right)^{2}}+\frac{5 s}{4 N \beta_{A}^{2}}>0
\end{aligned}
$$

The analysis of the functions is for $\alpha_{A} \geq 1 / 2$. Properties for $\alpha_{A}<1 / 2$ can easily be deduced by symmetry.

Convexity of $M\left(\alpha_{A}\right)$ Function $M$ is convex if and only if ratio $l_{B}$ changes monotonically along curve $M$. As $\alpha_{A}$ increases, $l_{B}$ increases along curve $M$ :

$$
\begin{aligned}
\partial\left(\frac{1-M\left(\alpha_{A}\right)}{1-\alpha_{A}}\right) / \partial \alpha_{A} & >0 \Leftrightarrow-M^{\prime}\left(\alpha_{A}\right)\left(1-\alpha_{A}\right)+\left(1-M\left(\alpha_{A}\right)\right)>0 \Leftrightarrow \\
\frac{1-M_{A}\left(\alpha_{A}\right)}{1-\alpha_{A}} & >M^{\prime}\left(\alpha_{A}\right)=-\frac{\partial \Delta \pi / \partial \alpha_{A}}{\partial \Delta \pi / \partial \beta_{A}}=\frac{\Phi+\Psi}{l_{A} N \Phi^{\prime}+l_{B} N \Psi^{\prime}} \\
& \Leftrightarrow \frac{1}{N l_{B}}>\frac{\Phi+\Psi}{l_{A} N \Phi^{\prime}+l_{B} N \Psi^{\prime}}
\end{aligned}
$$

which always true since $l_{A}>l_{B}, \Phi^{\prime}>\Phi$ and $\Psi^{\prime}>\Psi$.

Concavity of $G\left(\alpha_{A}\right)$ While analytical proofs for the properties of $G\left(\alpha_{A}\right)$ for general $F$ are complicated, it is easily shown numerically that $G$ has the required properties for a large number of specific functional forms and analytically when the production function is linear, i.e. $h F(l)=$ $h l$. In that case we have: $G^{\prime \prime}\left(\alpha_{A}\right)=-\frac{t 4 N}{5 s} 2 G^{\prime}\left(\alpha_{A}\right)\left[\left(1-\beta_{A}\right)^{-3}-\beta_{A}^{-3}\right]\left(\frac{1}{\left(1-\beta_{A}\right)^{2}}+\frac{1}{\beta_{A}^{2}}\right)^{-2}<0$ for any $\alpha_{A}>1 / 2$.

Existence of Equilibria (Points $I$ and $F$ )

We define $P\left(t, \alpha_{A}\right)=G\left(t, \alpha_{A}\right)-M\left(\alpha_{A}\right)$ where $G\left(t, \alpha_{A}\right) \equiv G\left(\alpha_{A}\right)$. Since this expression is symmetrical with respect to $\alpha_{A}=1 / 2$, we have $P\left(t, \alpha_{A}\right)=-P\left(t, 1-\alpha_{A}\right)$ and any properties of the function for $\alpha_{A} \geq 1 / 2$ can be derived by symmetry for $\alpha_{A} \leq 1 / 2$. 
Function $P\left(t, \alpha_{A}\right)$ has the following properties:

Property $1 P\left(t, \alpha_{A}\right)$ is continuous and increasing in $t$ : For any $\alpha_{A}$, we have $\partial \Delta w / \partial t<0$ and $\partial \Delta w / \partial \beta_{A}>0$ which implies $\partial G / \partial t>0$.

Property $2 P\left(0, \alpha_{A}\right)<0$ for any $\alpha_{A}>1 / 2$ : Along curve $M, \Delta \pi=\left(F\left(l_{A}\right)-l_{A} w_{A}\right)-$ $\left(F\left(l_{B}\right)-l_{B} w_{B}\right)=0$. This curve is below the 45-degree line, thus $l_{A}>l_{B}$. Moreover, $F(l)-w l$ decreases with $w$ and increases with $l$ since $w<F^{\prime}(l)$. Thus if $F\left(l_{A}\right)-w_{A} l_{A}=F\left(l_{B}\right)-w_{B} l_{B}$ and $l_{A}>l_{B}$, necessarily, $w_{A}>w_{B}$. Hence, $G$, where $w_{A}=w_{B}$, is below $M$.

Property 3 There exists $\bar{t}$ such that for any $t>\bar{t}, P\left(t, \alpha_{A}\right)>0$ for any $1>\alpha_{A}>1 / 2$. Using (6) and considering points $\left(\alpha_{A}, \beta_{A}\right)$ on the 45 -degree line, i.e. $\beta_{A} / \alpha_{A}=\left(1-\beta_{A}\right) /\left(1-\alpha_{A}\right)$, there always exists a $t$ such that $\Delta w<0$. This means that $G$ is above the 45 -degree line and since $M$ is always below this line, we have $G-M>0$. We note that for $t$ infinite, if $\alpha_{A}$ tends to $1, G\left(\alpha_{A}\right)$ tends to 1: the curve goes to the corner of the box.

Property 4 There exists $\underline{t}$ such that for any $t<\underline{t}, P\left(t, \alpha_{A}\right)<0$ for any $\alpha_{A}>1 / 2$ : This property is a consequence of properties 1 to 3 .

Property 5 For $\underline{t}<t<\bar{t}$, there exists $\bar{\alpha}$ such that $P(t, \bar{\alpha})=0$ : This property is a consequence of properties 1 to 4 . The point which satisfies $P(t, \bar{\alpha})=0$ is denoted by $I$ with coordinates $\bar{\alpha}$ and $\bar{\beta}$. When function $G\left(\alpha_{A}\right)$ is concave, this point is unique. Since $P^{\prime}\left(\alpha_{A}=1 / 2\right)>0$ and $P\left(\alpha_{A}=1\right)<0$, we have $P^{\prime}(\bar{\alpha})<0$ which implies that $G^{\prime}(\bar{\alpha})<M^{\prime}(\bar{\alpha})$.

\section{Equilibria Stability}

The equations of motion are given by (7) and (8) where functions $\mu$ and $v$ are assumed non-decreasing and continuous. Stability of the different equilibria is determined by looking at the Jacobian matrix $J$ of the system of equations given by (7) and (8) if both functions are continuous. We thus use this approach to establish the stability properties of $S$ and $I$, and use a graphical argument to establish the stability of $F$. Sufficient conditions for a stable equilibrium are that $|J|>0$ and trace $\operatorname{tr}(J)<0$ while for a saddle point, it is sufficient that $|J|<0$.

Proof: Since $\partial \Delta w / \partial \alpha_{A}<0$ we have that $\partial \dot{\alpha}_{A} / \partial \alpha_{A}=\mu^{\prime}\left(\Delta w\left(\alpha_{A}, \beta_{A}\right)\right) \partial \Delta w / \partial \alpha_{A} \leq 0$ and since $\partial \Delta \pi / \partial \beta_{A}<0$ we have that $\partial \dot{\beta}_{A} / \partial \beta_{A}=v^{\prime}\left(\Delta \pi\left(\alpha_{A}, \beta_{A}\right)\right) \partial \Delta \pi / \partial \beta_{A} \leq 0$. These two elements imply that $\operatorname{tr}(J)=\partial \dot{\alpha}_{A} / \partial \alpha_{A}+\partial \dot{\beta}_{A} / \partial \beta_{A}<0$. In addition, we have $\partial \dot{\alpha}_{A} / \partial \beta_{A}=$ $\mu^{\prime}\left(\Delta w\left(\alpha_{A}, \beta_{A}\right)\right) \partial \Delta w / \partial \beta_{A}$ and $\partial \dot{\beta}_{A} / \partial \alpha_{A}=v^{\prime}\left(\Delta \pi\left(\alpha_{A}, \beta_{A}\right)\right) \partial \Delta \pi / \partial \alpha_{A}$. Combining these 
different elements, we can write the determinant of the Jacobian matrix as

$$
\begin{aligned}
|J| & =\frac{\partial \dot{\alpha}_{A}}{\partial \alpha_{A}} \frac{\partial \dot{\beta}_{A}}{\partial \beta_{A}}-\frac{\partial \dot{\alpha}_{A}}{\partial \beta_{A}} \frac{\partial \dot{\beta}_{A}}{\partial \alpha_{A}} \\
& =\left(\frac{\frac{\partial \Delta w}{\partial \alpha_{A}}}{\frac{\partial \Delta w}{\partial \beta_{A}}} \frac{\partial \Delta \pi}{\frac{\partial \beta_{A}}{\partial \alpha_{A}}}-1\right) \mu^{\prime}\left(\Delta w\left(\alpha_{A}, \beta_{A}\right)\right) v^{\prime}\left(\Delta \pi\left(\alpha_{A}, \beta_{A}\right)\right) \frac{\partial \Delta w}{\partial \beta_{A}} \frac{\partial \Delta \pi}{\partial \alpha_{A}} \\
& =\left(\frac{G^{\prime}\left(\alpha_{A}\right)}{M^{\prime}\left(\alpha_{A}\right)}-1\right) \mu^{\prime}\left(\Delta w\left(\alpha_{A}, \beta_{A}\right)\right) v^{\prime}\left(\Delta \pi\left(\alpha_{A}, \beta_{A}\right)\right) \frac{\partial \Delta w}{\partial \beta_{A}} \frac{\partial \Delta \pi}{\partial \alpha_{A}}
\end{aligned}
$$

The terms outside the brackets being negative, we have sign $\{|J|\}=\operatorname{sign}\left\{\left(G^{\prime} / M^{\prime}\right)-1\right\}$.

Point S At point $S, G^{\prime}>M^{\prime} \Rightarrow|J|>0$.

Point I At point $I, G^{\prime}<M^{\prime} \Rightarrow|J|<0$.

Points F Points are stable according to a graphical argument.

\section{References}

[1] Abdel-Rahman, Hesham and Ping Wang. 1995. "Towards a general-equilibrium theory of a core-periphery system of cities," Regional Science and Urban Economics, 25, 529-549.

[2] Baldwin, Richard. 2001. "Core-periphery model with forward-looking expectations," Regional Science and Urban Economics, 31, 21-49.

[3] Becker, Gary. 1964. Human capital. Chicago: University of Chicago Press.

[4] Bentivogli, Chiara and Patrizio Pagano. 1999. "Regional disparities and labour mobility: The Euro 11 versus the USA," Labour, 13, 737-760.

[5] Brueckner, Jan, Jacques-François Thisse and Yves Zénou. 2002. "Local Labor Markets, Job Matching, and Urban Location", International Economic Review, 43, 155-171.

[6] De la Croix, David and Philippe Michel. 2002. A Theory of Economic Growth: Dynamics and Policy in Overlapping Generations. Cambridge: Cambridge University Press.

[7] Diamond, Charles and Curtis Simon. 1990. "Industrial Specialization and the Returns to labor", Journal of Labor Economics, 8 (2), 175-201. 
[8] Drapier, Carine and Hubert Jayet. 2003. "Les migrations des jeunes en phase d'insertion professionnelle en France," Revue d'Economie Régionale et Urbaine, 3, 355-376.

[9] Dumais, Guy, Glenn Ellison and Edward Glaeser. 1997. "Geographic concentration as a dynamic process," NBER N 6270.

[10] Duranton, Gilles and Hubert Jayet. 2005. "Is the Division of labour Limited By the Extent of the Market? Evidence from French Cities", CEPR DP 5087.

[11] Duranton, Gilles and Diego Puga. 2004. "Micro-foundations of urban agglomeration economies," in J.V. Henderson and J. Thisse (eds.), Handbook of Urban and Regional Economics, Amsterdam: Elsevier, pp. 2063-2118.

[12] Economides, Nicholas. 1989. "Symmetric equilibrium, existence and optimality in a differentiated product market," Journal of Economic Theory, 47, 178-194.

[13] Fujita, Masahisa and Jacques-François Thisse. 2002. Economics of Agglomeration, Cambridge: Cambridge University Press.

[14] Fujita, Masahisa, Paul Krugman and Anthony Venables. 1999. The spatial economy, Cambridge: MIT Press.

[15] Fukao, Kyoji and Roland Bénabou. 1993. "History Versus Expectations: A Comment," Quarterly Journal of Economics, 108, 535-542.

[16] Gill, Indermit, Fred Fluitman, and Amit Dar, eds., 2000. Vocational education and training reform. Matching skills to markets and budgets. Oxford: Oxford University Press.

[17] Hamilton, Jonathan, Jacques-François Thisse and Yves Zenou. 2000. "Wage competition with heterogenous workers and firms," Journal of labor Economics, 18(3), 453-472.

[18] Helsley, Robert and William Strange. 1990. "Matching and agglomeration economies in a system of cities," Regional Science and Urban Economics, 20, 189-212.

[19] Kats, Amos. 1995. "More on Hotelling's stability in competition," International Journal of Industrial Organisation, 13, 89-93. 
[20] Krugman, Paul. 1991a. "Increasing returns and economic geography," Journal of Political Economy, 99(3), 483-99.

[21] Krugman, Paul. 1991b. "History Versus Expectations," Quarterly Journal of Economics, $106(2), 651-667$.

[22] Krusell, Per, Lee Ohanian, Jose Ríos-Rull, and Giovanni Violante. 2000. "Capital-Skill Complementarity and Inequality," Econometrica, 68 (5), 1029-1054.

[23] Marimon, Ramon and Fabrizio Zilibotti. 1999. "Unemployment vs. Mismatch of Talents: Reconsidering Unemployment Benefits," Economic Journal, 109, 266-291.

[24] Martin, Philippe. 1999. "Public policies, regional inequalities and growth," Journal of Public Economics, 73(1), 85-105.

[25] Marshall, Alfred. 1920. Principles of economics, London: Macmillan.

[26] Matouschek, Niko and Frederic Robert-Nicoud. 2005. "The role of human capital investments in the location decision of firms," Regional Science and Urban Economics, 35(5), $570-83$.

[27] Maurel, Françoise and Béatrice Sedillot. 1999. "A measure of the geographic concentration in French manufacturing industries," Regional Science and Urban Economics, 29, 575-604.

[28] Miyagiwa, Kaz. 1991. "Scale economies in education and the brain drain problem," International Economic Review, 32, 743-759.

[29] Mobius, Markus and Raphael Shoenle. 2007. "The Evolution of Work," NBER Working Paper W12694.

[30] Ottaviano, Gianmarco, Takatoshi Tabuchi and Jacques-François Thisse. 2002. "Agglomeration and trade revisited," International Economic Review, 43(3), 409-435.

[31] Reichlin, Pietro and Aldo Rustichini. 1998. "Diverging patterns with endogenous labour migration," Journal of Economic Dynamics and Control, 22(5), 703-28. 
[32] Rosenthal, Stuart and William Strange. 2004. "Evidence on the nature and sources of agglomeration economies," in J.V. Henderson and J. Thisse (eds.), Handbook of Urban and Regional Economics, Amsterdam: Elsevier, pp. 2119-2172.

[33] Stevens, Margaret. 1994. "A theoretical model of on-the-job training with imperfect competition," Oxford Economic Papers, 46, 537-562.

[34] Wasmer, Etienne. 2006. "Interpreting Europe-US Labor Market Differences : the Specificity of Human Capital Investments", American Economic Review, 96(3), 811-831. 


\section{Recent titles \\ CORE Discussion Papers}

2008/9. Yves SMEERS. Gas models and three difficult objectives.

2008/10. Pierre DEHEZ and Daniela TELLONE. Data games. Sharing public goods with exclusion.

2008/11. Pierre PESTIEAU and Uri POSSEN. Prodigality and myopia. Two rationales for social security.

2008/12. Tim COELLI, Mathieu LEFEBVRE and Pierre PESTIEAU. Social protection performance in the European Union: comparison and convergence.

2008/13. Loran CHOLLETE, Andréas HEINEN and Alfonso VALDESOGO. Modeling international financial returns with a multivariate regime switching copula.

2008/14. Filomena GARCIA and Cecilia VERGARI. Compatibility choice in vertically differentiated technologies.

2008/15. Juan D. MORENO-TERNERO. Interdependent preferences in the design of equal-opportunity policies.

2008/16. Ana MAULEON, Vincent VANNETELBOSCH and Wouter VERGOTE. Von NeumannMorgenstern farsightedly stable sets in two-sided matching.

2008/17. Tanguy ISAAC. Information revelation in markets with pairwise meetings: complete information revelation in dynamic analysis.

2008/18. Juan D. MORENO-TERNERO and John E. ROEMER. Axiomatic resource allocation for heterogeneous agents.

2008/19. Carlo CAPUANO and Giuseppe DE FEO. Mixed duopoly, privatization and the shadow cost of public funds.

2008/20. Helmuth CREMER, Philippe DE DONDER, Dario MALDONADO and Pierre PESTIEAU. Forced saving, redistribution and nonlinear social security schemes.

2008/21. Philippe CHEVALIER and Jean-Christophe VAN DEN SCHRIECK. Approximating multiple class queueing models with loss models.

2008/22. Pierre PESTIEAU and Uri M. POSSEN. Interaction of defined benefit pension plans and social security.

2008/23. Marco MARINUCCI. Optimal ownership in joint ventures with contributions of asymmetric partners.

2008/24. Raouf BOUCEKKINE, Natali HRITONENKO and Yuri YATSENKO. Optimal firm behavior under environmental constraints.

2008/25. Ana MAULEON, Vincent VANNETELBOSCH and Cecilia VERGARI. Market integration in network industries.

2008/26. Leonidas C. KOUTSOUGERAS and Nicholas ZIROS. Decentralization of the core through Nash equilibrium.

2008/27. Jean J. GABSZEWICZ, Didier LAUSSEL and Ornella TAROLA. To acquire, or to compete? An entry dilemma.

2008/28. Jean-Sébastien TRANCREZ, Philippe CHEVALIER and Pierre SEMAL. Probability masses fitting in the analysis of manufacturing flow lines.

2008/29. Marie-Louise LEROUX. Endogenous differential mortality, non monitored effort and optimal non linear taxation.

2008/30. Santanu S. DEY and Laurence A. WOLSEY. Two row mixed integer cuts via lifting.

2008/31. Helmuth CREMER, Philippe DE DONDER, Dario MALDONADO and Pierre PESTIEAU. Taxing sin goods and subsidizing health care.

2008/32. Jean J. GABSZEWICZ, Didier LAUSSEL and Nathalie SONNAC. The TV news scheduling game when the newscaster's face matters.

2008/33. Didier LAUSSEL and Joana RESENDE. Does the absence of competition in the market foster competition for the market? A dynamic approach to aftermarkets.

2008/34. Vincent D. BLONDEL and Yurii NESTEROV. Polynomial-time computation of the joint spectral radius for some sets of nonnegative matrices. 2008/35. David DE LA CROIX and Clara DELAVALLADE. Democracy, rule of law, corruption incentives and growth. 


\section{Recent titles}

\section{CORE Discussion Papers - continued}

2008/36. Jean J. GABSZEWICZ and Joana RESENDE. Uncertain quality, product variety and price competition.

2008/37. Gregor ZOETTL. On investment decisions in liberalized electricity markets: the impact of price caps at the spot market.

2008/38. Helmuth CREMER, Philippe DE DONDER, Dario MALDONADO and Pierre PESTIEAU. Habit formation and labor supply.

2008/39. Marie-Louise LEROUX and Grégory PONTHIERE. Optimal tax policy and expected longevity: a mean and variance approach.

2008/40. Kristian BEHRENS and Pierre M. PICARD. Transportation, freight rates, and economic geography.

2008/41. Gregor ZOETTL. Investment decisions in liberalized electricity markets: A framework of peak load pricing with strategic firms.

2008/42. Raouf BOUCEKKINE, Rodolphe DESBORDES and Hélène LATZER. How do epidemics induce behavioral changes?

2008/43. David DE LA CROIX and Marie VANDER DONCKT. Would empowering women initiate the demographic transition in least-developed countries?

2008/44. Geoffrey CARUSO, Dominique PEETERS, Jean CAVAILHES and Mark ROUNSEVELL. Space-time patterns of urban sprawl, a 1D cellular automata and microeconomic approach.

2008/45. Taoufik BOUEZMARNI, Jeroen V.K. ROMBOUTS and Abderrahim TAAMOUTI. Asymptotic properties of the Bernstein density copula for dependent data.

2008/46. Joe THARAKAN and Jean-Philippe TROPEANO. On the impact of labor market matching on regional disparities.

\section{Books}

Y. POCHET and L. WOLSEY (eds.) (2006), Production planning by mixed integer programming. New York, Springer-Verlag.

P. PESTIEAU (ed.) (2006), The welfare state in the European Union: economic and social perspectives. Oxford, Oxford University Press.

H. TULKENS (ed.) (2006), Public goods, environmental externalities and fiscal competition. New York, Springer-Verlag.

V. GINSBURGH and D. THROSBY (eds.) (2006), Handbook of the economics of art and culture. Amsterdam, Elsevier.

J. GABSZEWICZ (ed.) (2006), La différenciation des produits. Paris, La découverte.

L. BAUWENS, W. POHLMEIER and D. VEREDAS (eds.) (2008), High frequency financial econometrics: recent developments. Heidelberg, Physica-Verlag.

P. VAN HENTENRYCKE and L. WOLSEY (eds.) (2007), Integration of AI and OR techniques in constraint programming for combinatorial optimization problems. Berlin, Springer.

\section{CORE Lecture Series}

C. GOURIÉROUX and A. MONFORT (1995), Simulation Based Econometric Methods.

A. RUBINSTEIN (1996), Lectures on Modeling Bounded Rationality.

J. RENEGAR (1999), A Mathematical View of Interior-Point Methods in Convex Optimization.

B.D. BERNHEIM and M.D. WHINSTON (1999), Anticompetitive Exclusion and Foreclosure Through Vertical Agreements.

D. BIENSTOCK (2001), Potential function methods for approximately solving linear programming problems: theory and practice.

R. AMIR (2002), Supermodularity and complementarity in economics.

R. WEISMANTEL (2006), Lectures on mixed nonlinear programming. 